the author's own material--are brought together a large number of facts and details hitherto scattered throughout the various scientific journals and publications, relating to the members of this interesting family. We hope Mr. Stretch will receive such encouragement from Entomologists as will reward him for his valued labors in this department, and stimulate him to further efforts.

Catalogue of the Phalaenidæe of California, No. 2, by A. S. Packard, jr., M. D. This is an octavo pamphlet of 40 pages, with one photograph plate, illustrating 24 new species, detailed descriptions of which are given in the accompanying letter-press, together with many other interesting. facts relating to other Californian species.

\title{
EDITORIAL, SUMMARY.
}

MR. RILEY RECEIVES A HANDSOME TESTIMONIAL.

The following correspondence explains itself:

$$
\left.\begin{array}{c}
\text { Acience Consulaire de France a St. Louis, } \\
\text { St. Louis, Mo., Feb. } 23,1874 .
\end{array}\right\}
$$

Prof. Chas. V. Riley, State Entomologist, St. Louis, Mo. :

DEAR Sir.- I have the honor to inform you that his excellency, the Minister of Foreign Affairs, has forwarded to me through the Consulate of New Orleans, the gold medal awarded to you by the Minister of Agriculture and Commerce, of France, in appreciation of discoveries in economic entomology, and especially of services rendered to French: grape culture.

I congratulate you sincerely on this well deserved compliment. It is: a proof that your talents and labors have been recognized by very high and competent judges.

Accept my assurance of the high regard with which I am, yours respectfully,

EMILE KARST, Agent Consulaire de France.

The medal is of gold, very heavy and handsomely finished. It is round, probabiy an inch and a half in diameter, and bears upon its face the head of the Goddess of Liberty, in bas-relief, with the words: "Republique Francaise." Upon the reverse is : 
“Mr. Riley, a St. Louis, Missouri, Services Rendus a La Viticulture Francaise, 1873," encircled by "Ministere de l'Agriculture et du Commerce."

The following is Mr. Riley's acknowledgement :

Emile Karst, Agent Consulaire de France :

St. Louis, FEB. 23,1874 .

My Dear Sir. - Your favor of to-day is at hand. Knowledge, to the seeker after it, brings with it a reward far higher and more lasting than any outward token. Yet am I gratified to receive this testimonial of appreciation from the French Republic; because it shows that, while endeavoring; as a servant of the State of Missouri, to do what lies in my power for the advancement of agriculture within her borders, my efforts have been appreciated elsewhere. It illustrates that science-the true interpretation of nature's workings, and mighty lever to civilization and progress -is not local, but sheds her bright beams among all nations. It proves that the discovery of any fact tending to promote the comforts and conveniences of human existence, or, as Bacon so tersely expresses it, humanis commodis inservire, belongs not to one State alone, but to the world. Yours respectfully, C. V. Riley, State Entomologist.

THE PHYLLOXERA.

The following article from the Bulletin des Sceances de la Society d'Agriculture de France, $187^{2}$, p. 514, may be of interest to some of our vine-growers as showing the good effect of an application of soot for the destruction of the grape-vine root gall-louse. However, not having tried the soot ourselves, we can only give the experience of others, and add that Dr. Erni, formerly chemist to the Department of Agriculture, in a letter from Berne, Switzerland, has also highly recommended the use of soot for the same in sect.

"M. Rogier, mayor of Poule Gard, exhibited to the central society of agriculture the results obtained by the use of soot in the treatment of vines attacked by the phylloxera. A young vine attacked by this insect in 1869 , was treated with soot put at the foot or root of each stem, in the quantity of a half kilogram, (about one and one-tenth of a pound.) The vine recovered. The following years all the stems which composed it were smoked with soot. This vine has a remarkable vigor, while the neighboring vines were dead or seriously injured. All vines treated with 
soot, used as a preservative compost, are healthier, although surrounded with diseased vines."

We give the above extract for what it is worth, and hope some of our correspondents will try soot and report the result to the Department, as we have scarcely any of these destructive insects in our own immediate neighborhood. In reference to this insect, the grape-root gall-louse, the Department has received a very interesting letter from Mr. George W. Campbell, of Delaware, Ohio, in which he expresses his opinion that the aphis (pempligus) affecting the leaves and that upon the roots are not identical. He says :

"I have since then found in two instances what were doubtless eggs of the phylloxera (root-gall-louse) upon diseased roots the same as those within the galls, but solitary, and not in clusters as in the galls. This, I think, settles the question that the aphides infesting the roots are propagated under ground, upon the roots, and that they are probably not the same as are propagated in the galls upon the leaves."

Mr. Campbell also sent specimens of the roots injured, together with numerous root gall-lice clustered upon them, but although carefully examined with the microscope, we failed to find any eggs whatever upon the roots sent. These roots, however, have been planted just as received, with the insects upon them, in a fower-pot, and placed in a large wardian case in close contact with other pots containing healthy vines, in order to find out if the insects will pass from one vine to another during the winter, and if the healthy roots will next season be infested with either root or leaf gall-lice. We give Mr. Campbell's remarks merely to stimulate further inquiry into the identity of the two insects, as many naturalists have stated them to be merely varieties of the same insect. In France, it appears that flooding the vineyards at certain seasons to drown the insect out has been recommended, but this plan, even if successful, could only be carried out in level places, and could not be adopted in side-hill vineyards. - Monthly Report of the Department of Agriculture.

Correctron.-We would draw attention to an error which appeared in Ir. Summers' advertisement last month, and which will be found corrected in the present issue. It is in reference to the time up to which shares may be secured of the material to be collected in the lengthened tour he is about to undertake. It should be up to December, I874, instead of April; after that date specimens only will be for sale; we have a few yet to dispose of,--parties desiring them will please address our Secretary. 